\title{
VIDA Y OBRA DE UN SANTO VARÓN: JOAQUÍN DÍAZ DE RÁBAGO. TEÓRICO E HISTORIADOR DEL COOPERATIVISMO (1837-1898)
}

\author{
Por \\ RAIMUNDO GARCÍA DOMÍNGUEZ \\ «BOROBÓ»
}

Dedicado a la Condesa de Fenosa

y al Marqués de Bradomín

En la segunda mitad del siglo XIX descuella, en Santiago de Compostela, la singular figura de don Joaquín Antonio Díaz de Rábago y Díaz de Mier, cuyos estudios sobre sociología y economía sorprenden por su avanzado criterio, dentro de la estricta ortodoxia de su pensamiento católico a machamartillo. Por ello cabe incluirle en mi programada Galería de revolucionarios de antaño, aunque su ideología pudiera parecer, a ciertos espíritus, notablemente reaccionaria.

Nacido en la villa de Muros, el 6 de Mayo de 1837, fue bautizado Joaquín Antonio al día siguiente en la iglesia parroquial de San Pedro ${ }^{1}$ como hijo del coronel de Infantería, D. Joaquín Díaz de Rábago y Díaz de Terán, y de su esposa, doña Antonia Díaz de Mier y Gutiérrez de Terán. Al nacer «en pleno ambiente militar, recibiendo todavía los reflejos gloriosos de su padre el coronel Díaz de Rábago, del Batallón Literario Compostelano (famoso por batirse heroicamente contra las tropas napoleónicas, en la Guerra de la Independencia), se decide la vocación del futuro autor del Crédito Agrícola, dejándose llevar de los dulces arrullos de la ciencia

"CUADERNOS DE ESTUdIOS GALLEGOS", Tomo XLV, Fascículo 110, Santiago 1998. 
que con voz de sirena le llamaba (escribe Barcia Caballero en su panegírico). Y cerrando las puertas del alma a la tentación de gloria que le rodeaba como un nimbo de luz, comparte sus horas de adolescente entre los estudios tal vez sobrado graves a que se sentía atraído, y el culto fervoroso por su madre a la sazón enferma y paralítica» ${ }^{2}$.

El coronel Díaz de Rábago pertenecía a una estirpe burgalesa, una de cuyas ramas se afincó en Galicia. Inició su carrera militar en el famoso Batallón Literario, compuesto por estudiantes de la Universidad de Santiago, que combatió contra los invasores franceses en la Guerra de la Independencia. Lo mandaba el marqués de Santa Cruz de Rivadulla y todos los escolares combatientes de esta Palladis Legio poseían la graduación de cadetes. A Rábago lo cita Armando Cotarelo en las Memorias de un escolar de antaño, como uno de aquellos valerosos cadetes, algunos de los cuales, como Rodil y García Camba, alcanzaron luego los entorchados de general ${ }^{3}$.

\section{EL AVENTAJADO UNIVERSITARIO DE COMPOSTELA}

Contaba diez años el niño Joaquín cuando inició en Compostela sus estudios de Bachillerato que realizó brillantemente. Luego cursó la carrera de Derecho y la de Filosofía y Letras, ambas con las máximas calificaciones. Fue discípulo predilecto, en la Cátedra de Economía Política y Hacienda Pública, del insigne profesor catalán D. Joaquín Sanromá, maestro asimismo en esas disciplinas de Eugenio Montero Ríos. Aún no había salido de las aulas, cuando el 17-XII-1856, leyó en aquella Cátedra de Economía, un discurso sobre La tasa legal de los productos. Rechazó esa tasa, considerándola contraria a la libertad, al interés individual y a la ley de competencia. Sustenta entonces los principios del liberalismo económico, condensados en la frase de Jovellanos que encabeza el discurso, en la que el patricio asturiano sostenía que a su «sombra crecerán la industria, el comercio, la población y la riqueza».

$\mathrm{Al}$ recibir, poco después, el joven Díaz de Rábago la investidura del grado de Licenciado en Derecho, lee otro estudio acerca de la Patria potestad de la mujer. Tema puramente jurídico, aunque entraña asimismo un problema social: el de la influencia de la mujer en la sociedad a través de sus funciones específicas en el hogar. Recuerda «como el Cristianismo 
levantó a ésta del fango en que la antigüedad la había sumergido», e invítala a escoger entre dos caminos que se le ofrecen: «o la rehabilitación de las pasiones, es decir, la emancipación sansimoniana, o el ejercicio de las virtudes, la emancipación cristiana» ${ }^{5}$.

Completa, algo más tarde, su labor universitaria con la tesis doctoral que versó sobre La teoría de Malthus. Defiende a éste y ataca a los malthusianos. «Estos -dice- tergiversaron la doctrina del maestro -que Rábago equipara al celibato católico-. Proclama ya el principio de la solidaridad humana y termina afirmando que sólo en el catolicismo se encuentra la solución de todos los problemas sociales, reafirmando su catolicismo social e iniciando su filosofía cooperativista fundada en la solidaridad» ${ }^{1}$.

Comparte tales trabajos jurídicos y sociológicos Díaz de Rábago con sus «aficiones literarias que se van por cierto apagando en el curso de la vida», según él mismo confesó. Siempre sintió entusiasmo por la literatura hebráica y por su lengua, que D. Joaquín dominaba. Por ello, «en el año 1860, Pedro Labán y Larroya, director general de Instrucción Pública, le encomienda el desempeño interino de la Cátedra de Lengua Hebrea de la Universidad compostelana; al mismo tiempo, es designado por el rector Juan José Viñas, secretario interino de la Facultad de Filosofía y Letras».

A esta época pertenecen ciertos ensayos del joven universitario, hoy todavía inéditos, entre los que sobresalen: «Los primeros pobladores de España y puntos de la Península donde se establecieron, tesis de doctorado en Filosofía y Letras, en la que se analiza la importancia que tienen las lenguas para el conocimiento del origen de los pueblos, y Fray Martín Sarmiento como adelantado en la creación de bibliotecas, informe leído el 28 de abril de $1871 »^{6}$.

\section{EL PIADOSO SEÑOR SANTIAGUÉS}

Durante unos años parece concentrarse la atención del joven profesor en cierta piadosa y benéfica tarea. «La presidencia del Consejo particular de las Conferencias caritativas de San Vicente de Paúl, que desempeñó algún tiempo Díaz de Rábago, proporcionole ocasión para escribir tres hermosos discursos, donde el vigor del entendimiento y la profundidad

"CUADERNOS DE ESTUDIOS GALLEGOS", Tomo XLV, Fascículo 110, Santiago 1998. 
del saber corren parejas con el afecto compasivo hacia los pobres» ${ }^{5}$. Esos tres discursos han sido publicados en sus Obras Completas. (O.C. VI).

Trató en el primero acerca de la Observancia del reglamento de las Conferencias de S. Vicente; leído en la Junta General de las Conferencias de Santiago, celebrada el 13-XII-1863, posee una honda implicación socialcristiana como piadosamente señala Rábago, al referirse a «la mejora moral del socio por medio del pobre». Casi tres años después, 1-III1866, pronuncia otro semejante en similar ocasión y un bienio más tarde, el 28-IV-1868, lee ante dicha Junta General, otro discurso sobre el Nacimiento de la caridad y su desenvolvimiento dentro de la Iglesia Católica. Afirma que la Iglesia «es la única poseedora de la caridad», aduciendo que ésta nació con el Cristianismo y que, mediante sus instituciones caritativas salvó a la humanidad de sus mayores crisis.

A esos tres discursos quedó limitada la serie que don Joaquín pensaba escribir destinada a «purificar el concepto de la caridad amalgamado con escorias filosóficas que es preciso reducir», como anunciaba en su primera oración.

Desde que comenzó sus estudios en Santiago y hasta el final de su vida residió Díaz de Rábago en la ciudad jacobea, si bien las temporadas veraniegas las pasaba, con su familia, en su pazo de La Puebla del Deán, ahora hermosamente restaurado por su nieta, la Condesa de Fenosa. La vinculación de don Joaquín con La Puebla ha sido tan entrañable que incluso algún cronista de esta villa le hizo nacer en el bello pazo donde ciertamente habría de morir el insigne muradano ${ }^{7}$.

Contrajo matrimonio Díaz de Rábago con María de la Concepción Aguiar Pazos, de hidalga familia gallega, la cual le dio numerosos hijos. Once, de los cuales murieron cinco antes de fallecer el padre, según la Enciclopedia Gallega ${ }^{6}$, si bien el citado cronista menciona los nombres de ocho hijos que sobrevivieron a don Joaquín?

Fuesen tres o cinco los vástagos del eminente sociólogo que sucesivamente le precedieron en su muerte, la verdad es que «uno a uno fueron desfilando camino de la eternidad muchos de aquellos pedazos de su alma; y a proporción que el nido iba quedando vacío, encanecían los cabellos del padre y se apagaba el fulgor de sus ojos y sus energías desmayaban y su cuerpo se doblegaba bajo la pesadumbre del dolor», como recordaba Barcia Caballero, su primer biógrafo. Quién añadía que «una vez y otra vez y otras muchas sintió su corazón desgarrado por el mayor de los dolo- 
res; y siempre recibió la sangrienta herida repitiendo aquellas palabras de Job, su poeta predilecto: Dominus dedit; Dominus abstulit. Sicut Domino placuit, ita fatum est.»².

«Rábago sentía y vivía todo lo que escribía; así ponía en todo pedazos de su corazón y de su alma; y no hay uno solo de sus libros que no encierre párrafos capaces de arrancar lágrimas», sostenía el sentimental don Juan. Así ocurre en el emotivo artículo de don Joaquín sobre El limbo de los niños (Creencias populares de Galicia) en que refleja su paternal tristeza. (O.C.V).

Narra en su primera parte el rito tradicional gallego del día de la Candelaria, en el cual las mujeres del pueblo asisten «a misa hincadas las rodillas, húmedos los ojos, el corazón palpitante y teniendo en las manos o delante de sí candelas encendidas, que marean el número de los hijos de que han abortado o que no han arribado, por cualquiera causa, a ser regenerados con las aguas salutíferas del bautismo». Busca las raíces de esta conmovedora costumbre en las fiestas februas o purificatorias de los romanos, y en el «precepto del Levítico tocante a la impureza legal de la mujer parida» que regía en el pueblo judío.

Contrasta Díaz de Rábago, en la segunda mitad de su artículo, al limbo de los niños con el infierno que padecían en vida los obreros infantiles en la industria del siglo XIX, particularmente en Inglaterra. Describe los horrores del trabajo de aquellas criaturas en minas y fábricas con espeluznante exactitud, que hace pensar en los relatos de Carlos Dickens y en las denuncias de Carlos Marx sobre el mismo tema.

Pero la mentalidad cristiana de don Joaquín le hace exclamar al principio de otro artículo bellísimo: «¡Dolor, tu no eres un mal!». Tan natural es al hombre el dolor que se diría ser su elemento pues hasta las santas alegrías y los transportes hueros del amor se traducen por lágrimas y suspiros. ¿Por ventura amar no es padecer? Y al trasladarse Díaz de Rábago de la vida exterior a la íntima y religiosa, halla al dolor sentado en sus umbrales, ora en el Remordimiento y la Penitencia, ya en la Humildad y la Caridad. Aprecia además que el dolor tiene su voluptuosidad: en «ese dulce goce que el alma experimenta al anegarse voluntariamente en las aguas de una suavísima pena; la melancolía, privilegio de las naturalezas poéticas y ricas en sentimiento».

Sería curioso contrastar esta suerte de masoquismo católico y romántico, exaltado por don Joaquín (O.C. V), con el concepto que Pío Baroja 
tenía del dolor cuando compuso, pocos años después del escrito de Rábago, su tesis doctoral acerca de ese tema, que no conocía tan en su carne como aquel: « ¡Oh! Bien podía hablar del dolor Díaz de Rábago, maestro de la ciencia del sufrir», cual le denominaba Cabeza de León ${ }^{5}$.

\section{EL ELEGANTE ESCRITOR COMPOSTELANO}

Durante unos quince años la voz y la pluma de Joaquín Díaz de Rábago parecen haber entrado en un período de silencio. Quizá escribiese entonces alguno de los artículos que aparecerían como inéditos y sin fecha en sus Obras Completas; acaso hayan sido originales suyos ciertos informes de la Sociedad Económica, elaborados en esos tres lustros, sin mención expresa del autor. ¿Qué hizo entonces, en ese tiempo, don Joaquín?. Seguramente lo que tantos compostelanos anónimos: leer sin descanso, estudiar, reflexionar. Ello explicaría su inmenso saber que pondera Barcia Caballero:

«Apuntado queda que su erudición era verdaderamente asombrosa. Éralo en tanto grado que por mi cuenta no conocí otra tan completa, tan vasta y tan variada. Punto menos que imposible se hacía el citar alguna obra y mucho más si era clásica o de fondo, que no conociese a conciencia. Completaba esta cultura con extensos y fundamentalísimos conocimientos gramáticos y filológicos que constituían una verdadera especialidad $»^{2}$.

Ha de considerarse que en esa época, de extraordinario esplendor cultural en Santiago, convivían en Compostela polígrafos de la talla intelectual de D. Manuel Murguía y de D. Gumersindo Laverde, el sabio maestro de Menéndez y Pelayo, a quien el propio Barcia -tan amigo y admirador de sus grandes vecinos- llamaba «Pontífice máximo de aquel minúsculo Areópago» ${ }^{8}$.

Destacaría Díaz de Rábago entre los numerosos cultivadores de las letras que existían allí, en los años de aprendizaje de Valle-Inclán; pues la más saliente era, según Barcia Caballero, su personalidad de escritor. «En ese terreno su superioridad era indudable. Correctísimo, discreto, atildado, son sus trabajos verdaderas filigranas, encajes de palabras tejidas por 
el arte. Alguien creía por esto que limaba y corregía con exceso sus escritos. No era así. Aquellos párrafos armoniosos, llenos, sonoros y pulidos brotaban de su pluma sin esfuerzo y casi sin intentarlo en fuerza de su hábito y de su prodigiosa cultura literaria».

Gastaba más tiempo Rábago en buscar el punto de vista original y nuevo del asunto, atinando siempre con la palabra precisa y el giro elegante, al transmitir «el sentimiento de vida que por doquier late y palpita» en su obra. Parecía paradógico a sus coetáneos que un economista pudiese poseer tal capacidad estética, pues «bajo aquella envoltura de ciencia latía un corazón de poeta», que se manifestaba más libremente «con su genial galanura y su sin par terneza» en los contados escritos puramente literarios de D. Joaquín ${ }^{2}$. Así Cabeza de León resalta, conmovido por el más sagrado de ellos: «¡Cuán hermosamente sentida la invocación con que saluda a la Reina de los Ángeles en aquella breve plegaria henchida de amorosa ternura, en aquel iDios te salve! (O.C. V) que puede figurar dignamente entre las páginas más brillantes del sublime e inacabable poema que los hombres vienen entonando en loor de María!» ${ }^{5}$.

\section{EL HONRADO PATRICIO DEL CRÉDITO AGRÍCOLA}

Había ingresado Díaz de Rábago, en 1861, como socio de número en la Real Sociedad Económica de Amigos del País de Santiago, pero es a principios de 1880 cuando la actividad intelectual de don Joaquín cobra un impulso extraordinario al desarrollar su tarea, en dicha Sociedad, como ponente de una serie de informes de excepcional valor. Comenzó con el «Informe sobre si es conveniente que por la Excma. Diputación Provincial de La Coruña se establezcan Pósitos o Bancos agrícolas en las capitales de partido». (O.C. IV). Lo firmaron con él otros dos ponentes, Elías Rivas Martínez y Modesto Fernández Pereiro, el 24-II-1880. Fue escrito en respuesta a una petición de la mencionada Corporación y debió ser obra exclusiva de Rábago pues anticipa lo que ha de desarrollar muy pronto en su obra capital.

La Comisión de la Económica se vio «en la dura necesidad de pronunciarse contra el planteamiento de Pósitos, que en las capitales de partido y por cuenta de la Diputación de esta provincia, faciliten granos y dinero a los labradores necesitados para la siembra y el consumo, porque orga-

"CUADERNOS DE ESTUDIOS GALLEGOS", Tomo XLV, Fascículo 110, Santiago 1998. 
nismos destinados a remediar las crisis de subsistencia son ineficaces y pueden degenerar en contraproducentes». También se opuso la Comisión al establecimiento de Bancos agrícolas en las capitales de partido que facilitasen dinero y semilla a los labradores necesitados «porque la naturaleza de la institución puramente mercantil, no se compadece con la misión que en nuestro organismo social cumple realizar a la administración».

Al informar así, Rábago y sus consocios sentían «aprisionado el corazón, que no consiste en un guarismo, como el de los Economistas se ha dicho, sino que late también con violencia cuando el socorro del infortunio y de los males del hombre se trata». Les dolía informar negativamente sobre aquel pensamiento de la Diputación tan honrada y benéfica, que «para mejorar la situación de la gente de nuestros campos no ha de hallarse en flor, sino que deber es de todo patricio, y más cuando su consejo se reclama, contribuir a depurarlo, enderezarlo, a hacerlo viable y asequible». Y sugerían que «otras instituciones económicas, aunque en menor y más modesta escala, serían a propósito para dispensarle el amparo que merecen, dando su beneplácito a la creación de Bancos agrícolas privados, subvencionados por la Diputación». (O.C. IV).

«Atrájole como imán poderoso la cuestión fiduciaria -señalaría más tarde Alfredo Brañas, a propósito de D. Joaquín Díaz de Rábago-. Su primer ensayo le sugirió otro más extenso y vino a darle pie la información abierta en 1881 por la Dirección General de Agricultura acerca del mejor modo de organizar el crédito agrícola en España ${ }^{4}$. La respuesta fue el magno estudio de Rábago, El Crédito Agrícola, que habría de ocupar, con el reseñado Informe sobre los Pósitos y Bancos Agrícolas, los cuatro primeros volúmenes de sus Obras Completas; publicadas póstumamente, si bien El Crédito Agrícola ya había sido impreso por vez primera, en los talleres de La Gaceta de Santiago, en 1883.

La información había sido abierta mediante un «Interrogatorio» que figuraba en el Real Decreto del 17-I-1881, firmado por Fermín Lasala, Duque de Mandas, ministro de Fomento en el Gobierno de Cánovas, entonces en el poder. Venía a ser la reproducción casi exacta de otro «Interrogatorio», mandado hacer treinta años antes, por el ministro gallego de Fomento, Seijas Lozano, el 17-IV-1850, en pleno reinado de Isabel II. No habiendo respondido éste satisfactoriamente por los ayuntamientos y corporaciones a los que se interrogaba, y al no ser tampoco abundantes los 
datos suministrados por los distintos censos de la población, efectuados hasta esos días, para el estudio de la producción agrícola, hubo de basarse Díaz de Rábago en otros documentos españoles y extranjeros que cita con profusión.

Presentó Rábago su informe a la Sociedad Económica el 15-IV-1882, dando «lectura a sus dos primeras partes, combinándola con el despacho y discusión de los demás asuntos, en el decurso de los meses de Abril a Julio del mismo año». Luego suspendió la lectura al haberse ausentado de Santiago, seguramente para irse de veraneo a La Puebla, donde habrá tenido «ocasión y espacio para retocar la parte tercera con arreglo a documentos y datos más recientes». Por ejemplo el Proyecto del Código de Comercio debatido ese año en las Cortes; distinto al publicado en 1881, que fue el que don Joaquín utilizó en la redacción de las dos primeras partes de su informe (O.C. II), el cual fue escrito con anterioridad al vigente Código Civil.

El Crédito Agrícola, por su dimensión y su calidad, es indudablemente la principal obra de su autor. «Obra -a juicio de Brañas- de extraordinaria erudición, de sana doctrina económica, grande originalidad y alcances tales, que es sin disputa la mejor producción de esta clase que salió a luz en España, en nuestro siglo, y puede competir con las similares publicadas en estos tiempos en Francia, Alemania, Italia, Bélgica e Inglaterra» ${ }^{4}$. Dentro de la amplitud de su concepción «El Crédito Agrícola contiene ya en germen todas las publicaciones posteriores de Díaz de Rábago incluidas las sociales» ${ }^{1}$.

La magna obra de Díaz de Rábago se condensa en un «Resumen» final, compuesto de XXXV Puntos, del que haremos una sucinta síntesis. Comienza ocupándose exclusivamente de la constitución agraria de Galicia en los tres puntos iniciales. Según él está determinada por dos factores: el primero, la subdivisión de la propiedad y la correlativa densidad de población, con el elevado número de jornaleros censados, que en realidad son en su mayoría arrendatarios o propietarios de parcelas. Resalta que la agricultura se ejerce en familia, mediante la forma jurídica y peculiar de compañía gallega. El segundo factor sería el foro, desarrollado abusivamente, y que aún siendo tan fecundo en bienes en otras regiones, exige en Galicia su redención, respetando los intereses legales; constituía un obstáculo para el establecimiento del crédito agrícola. Examina las diversas formas de cultivo -directo, aparcería y arrenda-

"CUADERNOS DE ESTUDIOS GALLEGOS", Tomo XLV, Fascículo 110, Santiago 1998. 
miento- efectuadas de forma rutinaria; operando el labrador con insuficiente capital o prestado con frecuencia. «La usura domina», afirma don Joaquín, al concluir su introito gallego que da paso a su estudio más universal.

Aborda luego don Joaquín el problema general del crédito agrícola, que nace del hipotecario «por el deseo de ampliar sus beneficios a los cultivadores que no tienen inmuebles que ofrecer en garantía de sus obligaciones». Presta detenida atención al desarrollo del sistema en Francia, la nación que más se había distinguido «en el estudio teórico de las cuestiones que suscita», parangonándolo con el tratamiento del tema en España. Examina después las distintas modalidades de arrendamiento en Bélgica, Escocia, Inglaterra e Irlanda, inclinándose por «la solución en los dominios de la aparcería agrícola».

Asegura Rábago que hasta su tiempo «los intereses de las clases cultivadoras permanecieron extraños a las combinaciones mercantiles del movimiento de crédito; en cambio la caridad acudió en su auxilio» fundándose en las diversas naciones institutos benéficos, tales como los montes agrarios de Italia semejantes a nuestros pósitos. Al declinar esos institutos, los «impacientes quieren que el Estado acometa la creación de Bancos agrícolas». Rábago insiste en los argumentos contrarios expuestos en su respuesta a la Diputación coruñesa, sosteniendo que la acción del Estado debe limitarse a ser indirecta. Alaba la colosal importancia de los bancos de Escocia y la estimable de los bancos rurales de Portugal que «hubieran sido preferible paradigma» del Proyecto de Código de Comercio entonces en debate.

Cree don Joaquín que el capital que necesita la agricultura podría obtenerse por «la condensación de las economías populares operada por el instrumento de las cajas de ahorro o de los bancos populares», si bien advierte que «más modernas aún que las cajas de ahorro son las distintas especies de sociedades cooperativas». Alude a las de consumo del tipo de Rochdale y estudia profundamente los sistemas alemanes de cooperación de crédito: los bancos de anticipos o populares Schulze-Delitzch, puestos al alcance de las clases trabajadoras, y las cajas rurales de préstamo del tipo Raiffeisen que atendían a las necesidades peculiares del crédito agrícola. Sin embargo Rábago todavía daba en 1882 la preferencia a «la ardorosa iniciativa de Shulze-Delitzch», por considerarla más segura y practicable.

"CUADERNOS DE ESTUDIOS GALLEGOS", Tomo XLV, Fascículo 110, Santiago 1998. 
Trataba el ponente compostelano de propagar en España estos sistemas alemanes, aunque previniendo a quienes los implantasen «contra el magnetismo de algunas ideas más impregnadas de filosofía socialista que de prudencia, como el préstamo de honor». Avisaba nuevamente de que «el apoyo del Estado es peligroso y contrario a los principios de la ayuda de si propio (selbsthülfe)». En suma la solución del problema del crédito agrícola requería para Díaz de Rábago ciertas condiciones generales, sociales, económicas y tanto como ello «moralidad en las costumbres y sentimiento religioso que las vivifique y sea freno de aviesas pasiones que la revolución social espolea». Porque -concluía- la concentración de la propiedad y la organización industrial de la agricultura, «ponen a la población rural en una pendiente por donde es fácil que resbale al socialismo agrario» (O.C. IV). Que sería la hidra para el bueno de don Joaquín.

La faceta de jurisperito, muy vinculado a su tierra, de Rábago aún se expresa en otros trabajos posteriores, tales como La Hipoteca independiente, leída en el Apóstol de 1886 (O.C. VI). Al año siguiente, 11-III1887 , da a conocer su exposición Sobre los proyectos de ley de redención de censos y crédito agrícola, en la cual aboga por la necesidad de redimir los foros, particularmente en Galicia (O.C. VIII).

Sobre foros trató nuevamente al fin de ese año, 31-XII-1887, en su prólogo al libro de Eduardo Vicenti (yerno de su condiscípulo Montero Ríos) titulado La Propiedad foral en Galicia (O.C. VII). «En la contienda entre el Marqués de Camarasa y don Eduardo Vicenti, Rábago se pronuncia por este último, es decir, a favor del dueño del dominio útil, porque se trata-dice- de una situación conflictiva entre la justicia legal y la justicia social, en que debe prevalecer la segunda, pues los bienes de orden social son superiores a los de orden puramente legal, rectificando lo que había escrito en El Crédito Agrícola en $1883^{1}$. Dado que en todos estos estudios jurídicos de don Joaquín resalta su superior sentimiento social.

\section{EL EMINENTE SOCIÓLOGO GALLEGO}

No podría ser de otro modo, ya que Díaz de Rábago ha sido sobre todo un eminente sociólogo y así lo demuestra la variada serie de temas que abordó en ese campo y siempre con la mira puesta en la práctica solución 
de los más acuciantes problemas de su país. Sirva de ejemplo, en cuanto a esto el par de eruditísimas monografías que redactó en 1885, para responder a sendas peticiones de información acerca de vitales asuntos hechos a los Amigos del País compostelanos.

Respondió la primera a la invitación de D. Gumersindo de Azcárate, como «redactor del magistral cuestionario» promovido por la Comisión de Reformas Sociales, presidida por D. Segismundo Moret, para «estudiar las cuestiones que interesan a las mejoras de las clases obreras, tanto agrícolas como industriales, y que afectan a las relaciones entre el capital y el trabajo» ${ }^{9}$. Tomó cuerpo en el admirable opúsculo La industria de la pesca en Galicia. Estudio sociológico (O.C. V), donde «comienza Rábago trazando el cuadro histórico de la pesca en Galicia, que alcanzó su siglo de oro en el XVI y decayó en el XVII a la par que el poderío español. A mediados del XVIII se inició su recuperación con la llegada de «los industriosos catalanes», de «espíritu emprendedor, genio laborioso y prácticas más adelantadas y lucrativas» que las de los pescadores gallegos ${ }^{1}$.

La actividad de los fomentadores catalanes causó de inmediato la ruina de los pescadores de las Rías, ocasionando una crisis económica local que luego fue superada entrándose en otra etapa de prosperidad; pero de esta se beneficiaban principalmente los empresarios forasteros que abonaban bajos precios por la pesca y «formaban cuerpo y haz enfrente de la Hacienda... y en contra de los pescadores».

Expuestos los antecedentes históricos del problema pasa Rábago a informar de cómo se verificaba el reparto de las ganancias entre los diversos agentes de la industria pesquera. Dice después que el ahorro no era la virtud característica de la clase pescadora; contrasta su despilfarro con la economía de la población labradora y propone don Joaquín dos medios para combatirlo: los pagos semanales y la instrucción elemental. Describe luego la participación de la mujer en las rudas tareas de la industria pesquera, refiriéndose de pasada a las pescantinas, porque «es peligroso tomar en labios a quienes tienen tan bien sentada reputación de desparpajo».

El panorama de la pesca gallega en 1894 era bien sombrío, mas don Andrés auguraba un porvenir halagüeño cifrado en la gran industria conservera. Si bien por encima de todos los signos favorables observaba «a la bienhadada asociación que centuplica el poder del hombre y es hábil para superar los más crecidos obstáculos». Para ella, «a diferencia de 
la agricultura que propende el aislamiento, la industria de la pesca ofrece facilidades y condiciones... que pueden muy bien aprovecharse para la mejora de la misma».

Con la asociación el otro medio para el desarrollo de la industria pesquera sería, ¿cómo no?, el crédito piscícola que en España no existía aún, pero si en Irlanda, país tan parecido al nuestro. Y termina don Joaquín declarando que en su estudio sociológico ha mirado precisamente «a los pescadores que no a la pesca», aunque sin santificarlos, dado «que es bajo y criminal adular a las clases populares, porque son la multitud, y no desengañarles en sus yerros, ni censurarlas por sus faltas».

La segunda monografía que redactó Díaz de Rábago en 1885 -año de la muerte de Rosalía de Castro y del Rey Alfonso XII- para cumplir un encargo hecho a la Sociedad Económica, trata de La Institución de Salvamento de Náufragos. Un lustro antes se había fundado, bajo el patronato de la Reina María Cristina la Sociedad Española de Salvamento de Náufragos, cuyo primer protector había sido el monarca. Contaba con 36 juntas locales diseminadas por todas las costas españolas, cinco de ellas, solamente, en Galicia. Una de éstas era la de Villagarcía de Arosa que deseosa de iniciar su cometido, pidió el patrocinio de los Amigos del País por mediación del socio de la Económica, D. José Antonio Parga y Sanjurjo, magistrado y escritor vivariense que habría de ser uno de los primeros académicos de la Real Gallega. Parga logró que su sociedad nombrase una Comisión «para informar sobre tan levantada proposición» que, como de costumbre, traspasó la encomienda a don Joaquín, quien la aceptó muy complacido.

«Cinco capítulos comprende la monografía de Díaz de Rábago. En el primero-Naufragios y náufragos- traza una reseña de las costumbres marítimas y leyes referentes a la navegación, en lo que toca al respecto hacia la vida y propiedad de los hombres». En los restantes capítulos informa acerca de las máquinas de salvamento y sobre «las Sociedades que en España y en el extranjero realizan la meritísima empresa de disputar al Océano vidas humanas, reseñando el último la historia de la Junta de Salvamento de Villagarcía, y exponiendo aquellos medios con que la Sociedad Económica de Santiago pudiera auxiliar a dicha Junta» ${ }^{5}$. Medios exclusivamente morales, entre los que destacaba el propio Informe, donde se proponían los medios materiales que cabría gestionar. Uno de ellos es ciertamente curioso, pues muestra la justa mentalidad recaudato- 
ria del economista murudano: «Deberían las provincias litorales pagar de alguna manera el privilegio de su favorecida situación a la orilla del mar, el mar es fuente de riqueza de que las del interior carecen, subvencionando las estaciones de salvamento que lo necesitasen».

Sin embargo, quizá en ninguna otra obra de don Joaquín luzca como en ésta su amplísima cultura literaria al servicio de su bondadoso corazón, dolorido al considerar la amarga suerte de tantos náufragos como en el mar han sido. Desde Ulises, víctima de la cólera rencorosa de Neptuno, a la vista de la isla de los Feacios, hasta los tripulantes del Forfashire, salvados en 1838, por la heroica hija del farero de Outer Ferner, en el mismo archipiélago donde habría edificado su monasterio San Cuthberto, abad de Lindisfarne, el San Telmo de los Northumbrios (O.C. V).

\section{EL SOCIAL PRECURSOR DE LEÓN XIII}

Como se observa, la preocupación social y cultural de Díaz de Rábago nunca se limitó a los temas regionales, ya que su pensamiento, en plena madurez intelectual, tenía alcance ecuménico y por ello se ocupa de temas tan candentes entonces como el de La jornada internacional de las ocho horas y el de El destajo a los que consagró sendos ensayos.

Al primer tema dedicó su habitual discurso del final de curso de la Económica, el 26-VII-1890. Su oportunidad era bien manifiesta y muestra como don Joaquín seguía puntualmente los acontecimientos sociales de mayor trascendencia en el mundo. Hacía solo un año que en París se había concentrado la atención de todos los pueblos civilizados. «Los periódicos de la época -y es muy comprensible- se ocupan sobre todo de la Exposición Universal, de las fiestas del Centenario de la Revolución Francesa, de las brillantes ceremonias y recepciones diplomáticas que se desarrollan sin cesar, de la gran revista militar del 14 de julio y también de la revista de batallones escolares, París está de fiesta», resalta Maurice Dommanget ${ }^{10}$.

Se concibe muy bien, pues, que la resolución tomada en el congreso marxista de la sala Pétrelle, celebrado durante aquella Exposición Universal, pasase desapercibida, a pesar de la histórica repercusión que habría de tener, incluso para muchos de los asistentes a los congresos obreros reunidos allí en aquellas fechas. Apenas se dieron cuenta de que los 
congresistas de la sala Petrelle -entre ellos, Pablo Iglesias-, además de crear la Segunda Internacional, habían acordado organizar cada $1^{\circ}$ de mayo una gran manifestación internacional con el preeminente objeto de que «los trabajadores intimen a los poderes públicos a reducir legalmente a ocho horas la jornada de trabajo». Nada más y nada menos.

Rábago había seguido desde sus orígenes el desarrollo de este histórico proceso, desde su punto de vista católico y burgués: «Por cierto misterioso cuanto apretado enlace -escribía- las exposiciones internacionales han traído como triste secuela, contraste sombrío de profusos esplendores, un avance o una recrudescencia de la agitación socialista revolucionaria... De la Exposición Universal de Londres de 1862, surge la Internacional. Las de Amsterdam y de Boston de 1883 dan lugar a una concentración de las fuerzas comunistas y socialistas, y a una aproximación entre las de Europa y América, con el fin de restablecer aquella Asociación temible, y trabajar en común para la Revolución Social». (O.C. VI).

Dice luego don Joaquín que la Exposición universal parisina de 1889 fue motivo para una serie de congresos y conferencias de todo tipo, particularmente durante el mes de julio. Entre ellas destaca que «rivalidades de jefatura» han separado en congresos diferentes a los llamados posibilistas, a quienes reforzaron los delegados de las Uniones inglesas de oficios (Trade Unions) y a los marxistas, discípulos de Karl Marx, legislador y cerebro que ha sido de la Internacional, y a los socialistas alemanes». Según Rábago no había verdadera oposición entre sus doctrinas, como lo revela el hecho de que las resoluciones de ambos congresos fueron muy semejantes: «Su síntesis es la aspiración e inmediata persecución de una legislación internacional del trabajo, que comprenda: la fijación de una jornada máxima de ocho horas; el descanso semanal; la interdicción absoluta del trabajo de los niños» y otros constantes anhelos de la clase obrera.

Todas estas aspiraciones del proletariado no asustan mucho a Rábago que describe los intentos de varios gobiernos europeos para darles solución. Pero sí le atemorizó la primera celebración de la fiesta internacional del trabajo, en el pasado mayo, que se había ido preparando, «entre tanto sociólogos y diplomáticos discutían flemáticamente teorías de leyes humanitarias sobre el trabajo industrial». Singularmente le angustió el gentío, el silencio y el orden de la mayoría de las manifestaciones: 
«Centenares de miles de obreros, como nunca se hubieron visto congregados, hasta 300.000 en Londres, han recorrido las calles de las grandes ciudades de la industria, sin pronunciar un grito, ni dejar sentir otro ruido que el confuso que produce la multitud y el de las pisadas de aquellas masas colosales, semejantes a ejércitos de Jerjes».

La manifestación de Londres, como la de Madrid, se postergó al domingo, 4 de mayo, dato que Rábago no consigna. Tampoco cuenta que en Barcelona el capitán general de Cataluña, Blanco, salió al balcón, muy impresionado, para saludar militarmente a los manifestantes. Pero sí anota, que como «resultado de la ondulación que produjo» en Santiago el $1^{\circ}$ de mayo, se desarrollaron ciertos acontecimientos en la ciudad «que terminaron noblemente por transacciones y acomodos». Lo que le hace exclamar: «iLoor a empresarios y obreros! ¡Un aplauso a la Autoridad!». (O.C. VI).

La armonía entre el capital y el trabajo era, efectivamente el ideal del eminente sociólogo, y llega incluso a propugnar la acción del Estado para proteger a los seres desvalidos y mejorar las condiciones laborales; pues era opuesto a encerrar «toda la ciencia de Gobierno en la conocida fórmula de laissez faire, laissez passer» y reducir la función del Estado «al oficio de Guardia Civil». Mas, en cuanto a la reglamentación del trabajo de los adultos, la postura de D. Joaquín era bastante adversa. Rábago admitía de buen grado la limitación de la jornada laboral por razones obvias de humanidad: «Las jornadas extenuantes, que agotan las fuerzas y chupan el jugo de los operarios, deben desaparecer de nuestra civilización, de la que son mancha: antes que los productos, los hombres». Sin embargo, le parecía inadmisible la teoría de los tres ochos, por juzgar que fomentaría la ociosidad y los vicios de la clase obrera. Estaba de acuerdo con la rebaja proporcional del salario, pues, en el caso contrario, sería una medida poco equitativa. Aún se sobreponía el economista liberal que empezó siendo don Joaquín, al reformista social que terminaría siendo, cuando señalaba ya que la solución del problema obrero estaba en el aumento de la productividad, que traería la baja de los precios y el alza de los salarios.

El virus socialista de que adolecía la teoría del ochorismo era el máximo motivo del rechazo de ella por Rábago, quien contaba siempre con la fórmula mágica para resolver éste y cualquier otro problema social: inculcar a patronos y obreros el cumplimiento del deber, ¿cómo no?, deber cristiano.

"CUADERNOS DE ESTUDIOS GALLEGOS", Tomo XLV, Fascículo 110, Santiago 1998. 
Reconocía don Andrés, sin embargo, la posible conveniencia de mayor ocio en casos como el de los niños, el ama de casa y el hombre que busca un tiempo para el estudio o el necesario esparcimiento. Desconfiaba, no obstante, de la ociosidad que fomentaba los vicios de los obreros y hacía de esta disipación del tiempo libre regla de conducta general de los trabajadores. Este razonamiento simplista, de aplicar lo singular a lo plural, no lo utilizaba un año después, cuando al tratar sobre El destajo, se preguntaba si porque algunos hacían mal uso de las ganancias que proporcionaba ¿deberá cerrársele al obrero el horizonte y constituirle... fatal e irremisiblemente en la pobreza». (O.C. VII).

Díaz de Rábago defendía calurosamente el sistema de destajo, porque si la justicia consiste en dar cada uno lo suyo, ninguna otra forma de trabajo resuelve mejor esta ecuación. Para él era muy superior el trabajo a jornal, dado que el destajo, apoyado en el interés individual, resultaba mucho más eficiente en orden a la productividad. Y sólo podría mantenerse un alto nivel de ésta, en caso de que se implantara la jornada de ocho horas, recurriendo al método ¿tan cristiano? del destajo.

Había tratado de este asunto en la inauguración del curso 1861/62 de la Escuela de Artes y Oficios de Santiago, cuyo Delegado Regio era. Cuatro años después, en similar apertura abordo El Problema social de la habitación. Señaló allí que el problema de la vivienda es la clave de la cuestión social por su incidencia en la familia «base fundamental de la sociedad». La gravedad del problema acentuada por la aglomeración industrial es ponderada por don Joaquín cerca ya del ocaso de su vida, en el que resultó ser su último estudio, que terminaba remachando con toda energía la tesis formulada en su juventud de que «sólo en el catolicismo social se encuentra la solución de todos los problemas sociales» entre los cuales el de la vivienda era, para el eminente sociólogo, el más grave. (O.C. VII).

La persistencia en ese pensamiento que tenía tan juveniles raíces en don Joaquín Díaz de Rábago es lo que hizo considerarlo como un precursor olvidado de la doctrina que el Papa León XIII expuso en su celebérrima encíclica Rerum Novarum. Los títulos que para ello podrían aducirse, son resumidos así por el jesuita Fernández de la Fuente en el libro que le consagró ${ }^{1}$ : 
"Díaz de Rábago, por los graves anatemas que en sus escritos lanzó contra el socialismo marxista, cuyos peligros e importancia no cesó de encarecer; por la sólida refutación que hizo de los errores de Owen, Saint-Simon, Lasalle y Fourier; por la descripción razonada de las causas que han originado el conflicto social, coincidiendo plenamente con las señaladas por León XIII en su Encíclica Rerum Novarum; por la atención que siempre prestó a las tensiones entre el capital y el trabajo; por la energía con que fustigó los abusos del capitalismo, calificándolo de "Rey tiránico de nuestras sociedades"; por su decidido empeño en fomentar el espíritu de asociación como uno de los remedios del problema obrero precisamente cuando la ola revolucionaria había desechado todo vínculo corporativo y abandonado la libertad individual a su propio recurso; por su calurosa defensa de la familia; por sus duras recriminaciones contra el trabajo de mujeres y niños; por el acendrado humanismo cristiano que impregna toda su sociología, y, en suma, por la importancia capital que daba a las enseñanzas y a la práctica de la religión católica como medio imprescindible para resolver las gravísimas cuestiones planteadas entre el capital y el trabajo..., por todas estas razones merece un puesto de honor junto a Ketteler, Balmes, Donoso Cortés y todos los grandes protagonistas del llamado Catolicismo social solemnemente refrendado por León XIII en su encíclica Rerum Novarum».

\section{EL ILUSTRE MENTOR DE LOS AMIGOS DEL PAÍS}

Esta ingente tarea que trasluce en la relación de méritos católicosociales que acabo de transcribir se desarrolló casi íntegramente dentro del ámbito cultural de la Sociedad Económica de Amigos del País, durante los años ochenta y noventa del siglo pasado, hasta su muerte. Fue tanta que, sin atenerme estrictamente al orden cronológico, la he distribuido ya entre las vertientes agraria, marítima y laboral que ocuparon a Don Joaquín en ese tiempo, las cuales se añaden a la jurídica y a la literaria que cultivó en su primera época. Queda aún toda su obra acerca del cooperativismo, que es la que más nos interesa, y con la cual finalizaré. Pero antes todavía tendré que reseñar los discursos y los opúsculos en los que trató sobre la propia historia y circunstancias de la Económica;

"CUADERNOS DE ESTUDIOS GALLEGOS", Tomo XLV, Fascículo 110, Santiago 1998. 
así como de las empresas promovidas por tan benemérita Sociedad compostelana.

Fundada en 1774 por el canónigo D. Antonio Páramo y Somoza, luego obispo preconizado de Lugo, la Sociedad Económica de Santiago desarrolló una actividad sin igual en Galicia, a lo largo de un siglo en que sólo la Guerra de la Independencia y la repercusión de las guerras carlistas pudieron poner coto a su acción. Su preocupación por el fomento de la economía gallega en todos sus aspectos - la agricultura, la pesca, la industria, el comercio y las comunicaciones- fue tan evidente como sus desvelos por el arte y la artesanía. Una serie de ilustres directores rigió sucesivamente a la Sociedad entre los mandatos de Páramo y de nuestro D. Joaquín, a quien le correspondió dirigirla en el trienio 1887-90. Los nombres del Arzobispo Malvar, el canónigo D. Antonio Sánchez, el conde de Gimonde, el Dr. Varela de Montes, D. Antonio Casares y otros no menos insignes, jalonan la historia de los Amigos del País que culmina en la etapa trienal de Díaz de Rábago.

Coincide plenamente este período en la «asombrosa eclosión del genio gallego que situamos en la Compostela de 1888, como anticipo, o preludio, de la genial efervescencia intelectual de 1898 en el Madrid de la Restauración del desastre». «Habría que detenerse en la Compostela de 1888 -señalaba yo en El fantasma de Valle-Inclán- para apreciar aquella asombrosa ebullición cultural que traslucía en la existencia de tantos periódicos políticos y burlescos, en los debates dentro y fuera de la Universidad, en la propia creación de la Tuna. Santiago estaba viviendo uno de los momentos de mayor tensión intelectual de su historia» ${ }^{8}$.

Por eso, ante tan espléndido panorama, nada parecía más equívoco que la visión contracultural de Compostela que ofrece Alejandro Pérez Lugín en su famosa novela La Casa de la Troya, donde llega a decir que pesaba «sobre la ciudad un pavor tremendo e inexplicable a los males que acarrea la que acaso allí nombraron funesta manía de pensar». De ahí que en mi mencionado libro arremeta contra el falso concepto troyano de Compostela, aduciendo:

«La Universidad de Santiago no era, precisamente, la catalana de Cervera. ¡Cuándo Brañas no tenía parada, hombre de infatigable acción! ¡Cuándo Murguía publicaba Galicia y, al ser repuesto en el Cuerpo de Archivos, reuniría en torno suyo, en la Biblioteca Univer- 
sitaria, a luminosas mentes juveniles! ¡Cuándo, en el mismo momento se publicaban en Santiago diez o doce periódicos! E apañaba datos López Ferreiro para publicar unha das súas obras máis esgrexias e máis ben feitas: Fueros Municipales de Santiago y su tierra, que aparecen en $1895 »^{11}$.

Hubiera debido añadir entonces a esta relación ponderativa el esfuerzo mental realizado esos años por don Joaquín como ponente y director de la Sociedad Económica, si bien en otras páginas de mi libro me refiero a cierto aspecto de su actividad cultural, como fue su intervención en el traslado de los restos mortales de Rosalía de Castro, desde el Camposanto de Adina hasta la iglesia conventual de Santo Domingo en Compostela, convertida desde ese momento en Panteón de Gallegos Ilustres.

Fue «la colonia gallega en la isla de Cuba, sintiendo latir en su pecho... el santo amor de la patria y de las glorias que esmaltan su corona», la que recaudó una importante cantidad para erigir a Rosalía un decoroso sepulcro en Compostela. Dicha colonia encargó a la Sociedad Económica de Amigos del País de Santiago de que llevase a cabo su proyecto. Era a la sazón director de la Económica D. Joaquín Díaz de Rábago, quien redactó una circular al país gallego pidiendo que contribuyera a la suscripción patriótica abierta para cubrir el total de los gastos que la traslación ocasionaría.

Díaz de Rábago se lamentaba en la circular, escrita el 1 de marzo de 1887, inserta en sus Obras Completas (O.C. VIII), de la sepultura en el cementerio iriense de Rosalía, «cuyas frías cenizas yacen en tumba modesta e ignorada en el atrio de la antigua Iría Flavia, junto a la orilla del camino, como la de Cecilia Metela, pero sin otra ornamentación que la sencilla y poética de que la ha rodeado la piedad cariñosa de la no rica familia, y el tapiz de césped que se apresta a tender encima la madre naturaleza como para abrigar en su sueño eterno a la inolvidable Décima musa Gallega», decía con su mejor retórica el bonísimo don Joaquín.

Animaba Díaz de Rábago, al término de su Circular, a los gallegos a que levantasen el monumento funerario y a «leer en su inscripción a la dedicatoria a Rosalía de Castro, y por bajo, como la firma del autor, Gallaecia fecit, se enorgullezca la posteridad de ser hija nuestra,

$Y$ con voz alta que a la gloria llegue

le diga al mundo que Galicia existe».

"CUADERNOS DE ESTUdIOS GALLEGOS", Tomo XLV, Fascículo 110, Santiago 1998. 
Pues don Joaquín, como era natural, concluía su circular con el vibrante par de versos de En las orillas del Sar. Y fue don Joaquín, como representante de los gallegos de Cuba, con el viudo de Rosalía, don Manuel Murguía, quienes eligieron a Santiago y a la capilla de la Visitación en Santo Domingo, para ser la ciudad y el emplazamiento del mausoleo. Asimismo escogieron entre varios modelos para éste, el del «hábil escultor don Jesús Landeira... con quien contrataron la ejecución del monumento en mármol, estilo Renacimiento».

Transcurrieron cuatro años desde aquella Circular hasta el 25-V-1891, en que se efectuó el traslado de los restos mortales de Rosalía. Consta en el acta notarial de ello que D. Joaquín Díaz de Rábago y Díaz de Mier siguió representando en ese fúnebre acto a los gallegos de Cuba, pero ya había sido reemplazado en la dirección de la Económica por el catedrático de Derecho Penal, D. Ramiro Rueda Neira, quien asimismo firma el acta. También comparecieron ante el notario, como organizadores del traslado los vicepresidentes de la Asociación Regionalista Gallega, Alfredo Brañas y Salvador Cabeza de León, «nombres que volverían a aparecer unidos siete años más tarde para, mediante la publicación de sus obras Completas, rendir homenaje póstumo al autor de El Crédito Agrícola» ${ }^{6}$.

\section{EL INSIGNE DIRECTOR DE LA SOCIEDAD ECONÓMICA}

El interés de Rábago por la propia historia de la Sociedad Económica se manifiesta primeramente en el discurso que pronunció en la sesión solemne celebrada, el 22-VII-1884, para la distribución de premios, por los Amigos del País. Disertó allí acerca del Origen de las Sociedades Económicas y su misión actual (O.C. VI), elogiando su extraordinaria contribución al progreso social y abogando por su perduración, como instrumentos regionales eficacísimos y descentralizadores.

Dos años después, 25-VII-1886, en semejante ocasión, trata sobre la Creación de una clase de Damas de Honor y Mérito en la Sociedad Económica (O.C. VI). Resaltó en este discurso «la excelsa figura de la mujer, su decisiva aportación a la civilización, y, por tanto, la conveniencia de incorporarla a las empresas de la Sociedad Económica, mediante la creación de una sección especial femenina, que contribuya con sus tareas específicas al progreso y bienestar social» ${ }^{1}$.

"CUADERNOS DE ESTUdiOS GALLEGOS", Tomo XLV, Fascículo 110, Santiago 1998. 
$\mathrm{Al}$ año siguiente, en la misma oportunidad, 26-VII-1887, el tema de su discurso fue Lo que ha hecho la Sociedad Económica de Santiago por la enseñanza popular (O.C. VI). Constituye la historia de la labor realizada por la Sociedad Económica de Santiago, durante el siglo que llevaba de existencia, en todas las enseñanzas que corresponden a las llamadas Escuelas de Artes y Oficios. Ese mismo año había sido nombrado don Joaquín, precisamente comisario regio y primer director de la Escuela de Artes y Oficios, fundada en Santiago mediante los auspicios de su antiguo condiscípulo y viejo amigo, D. Eugenio Montero Ríos, que regía esos días el Ministerio de Fomento.

En el acto inaugural del flamante centro, 19-II-1888, habló Díaz de Rábago sobre La enseñanza técnica industrial y forma y manera en que se aprestan a dispensarla las Escuelas de Artes y Oficios (O.C. VII). Resaltó «la oportunidad y conveniencia de la enseñanza técnica industrial en el momento histórico del tránsito de una economía agrícola a una economía industrial. Dicha enseñanza debería tener por objeto principal la industria popular o pequeñas industrias, de especial aplicación en Galicia, y adaptarse a las necesidades tópicas, por razones económicosociales» ${ }^{1}$.

Vuelve a hablar, en el verano del año siguiente, 26-VII-1889, en el acto de final de curso de los Amigos del País. Titula su disertación Reseña histórica de la Sociedad Económica de Santiago (O.C. VI). Completando lo dicho en sus discursos anteriores, «Menos licenciados y más industriales»-dice- es lo que necesita el país en un momento tan trascendental, que reclama urgentemente la elevación de los de abajo y un mayor bienestar para todos los ciudadanos.

Su última intervención en las solemnes sesiones de distribución de premios a los alumnos de las Escuelas de la Económica fue la del 26-VII1890, que versó sobre La Jornada Internacional de las Ocho Horas (O.C. VI), ya anotado anteriormente. Ese mismo año hubo de renunciar a la dirección de la Real Sociedad, «a causa de la afección pulmonar que padecía con curso irreversible» ${ }^{6}$. Estaba sometido ciertamente en ese lustro a una sobrecarga de trabajo, pues además de la dirección de la Económica y de la Escuela de Artes y Oficios, dirigía desde 1886, la sucursal del Bando de España en Santiago, creada en esa fecha.

Entre las iniciativas de la Sociedad Económica anteriores al período de Díaz de Rábago figuraba la construcción del ferrocarril de Carril a 
Santiago llevada a cabo por la compañía británica The West Galicia of Raillways. El grupo progresista de Santiago, encabezado por Eugenio Montero Ríos, que bulle en la prensa gallega y entre los Amigos del País, participa en al magna ilusión del siglo XIX, cifrada en las vías férreas. Uno de los más activos progresistas era Ramón Valle Bermúdez, el padre de Valle-Inclán, quien colabora en el semanario santiagués La Opinión Pública, tratando de incorporar a Galicia a «la civilización ferroviaria». Tanto que Valle Bermúdez es nombrado, el año 1863, secretario del Consejo de Administración del Ferrocarril Compostelano.

Los comunes anhelos y su coincidencia en La Puebla, donde ambos pasan muchos días en los pazos de sus respectivas estirpes, forja y consolida la amistad entre Ramón Valle Bermúdez y Joaquín Díaz de Rábago. Así cuando los hijos del primero, Carlos y Ramón del Valle Peña, van a estudiar Derecho a Santiago, será don Joaquín su mentor y vigilante de sus conductas. Además, parece ser que el joven Ramón anduvo enamorado de una de las hijas de Rábago. Quizá fuese aquella señorita que moraba «en cierto castillo encantado», a la que se refería Valle-Inclán en carta a Otero Acevedo. El castillo tal vez sería el hoy restaurado pazo de la Condesa de Fenosa, nieta de don Joaquín ${ }^{8}$.

La amistad entre los padres, prosigue entre los hijos, el insigne escritor y extravagante ciudadano don Ramón del Valle-Inclán y el piadoso y amable señor compostelano don Andrés Díaz de Rábago y Aguiar. Son compadres entre ellos desde que D. Andrés apadrinó en el bautismo al hoy marqués de Bradomín. Y su padrinazgo se patentizó de modo bien positivo en los primeros meses de la Guerra de España, cuando el joven estudiante de Medicina, Carlos del Valle-Inclán Blanco corrió evidente riesgo en aquellas sangrientas fechas de exterminio.

Recuperaré el hilo del texto, o mejor el raíl del tren, para concluir este capitulo, informando que el 8-VIII-1889, había pronunciado Díaz de Rábago, todavía en sus funciones de director de la Sociedad Económica, un discurso en la Inauguración de las obras del ferrocarril de Pontevedra a Carril (O.C. VI). Empalmaba de esa manera la línea inglesa de The West, desde Santiago al puerto arosano, con la red de las compañías nacionales que llegaba hasta Pontevedra. Aún pudo abrazar don Joaquín en la ciudad de Teucro a su viejo amigo Valle Bermúdez que era entonces secretario de la Diputación provincial pontevedresa y seguro que don Ramón oyó, con singular agrado, al antiguo partícipe de sus anhelos re- 
saltar «la importancia económico-social del nuevo ferrocarril en una zona tan poblada». Medio año después hubiera sido tarde para el encuentro, pues Valle Bermúdez falleció el 14-I-1890.

\section{EL IDEÓLOGO E HISTORIADOR DEL COOPERATIVISMO ESPAÑOL}

Entre todas las facetas de la ingente obra del eminente sociólogo gallego ninguna posee la importancia, para el mundo de nuestros días, que la consagrada al estudio del cooperativismo, pues conserva, a finales del siglo XX el mismo interés, la misma actualidad que en los amenes del XIX.

La preocupación de Díaz de Rábago por el fenómeno decimonónico del cooperativismo comienza a manifestarse en un artículo publicado, en 1883, en la Revista de la Sociedad Económica de Santiago. Trataba sobre La Cooperación inglesa de consumo (O.C. V). Y «debía ser el primero de una serie que, desgraciadamente, Rábago no continuó». Hace en él «un estudio minucioso y bien razonado del fenómeno distributivo, con la autoridad de un experto economista, de un jurista imparcial, de un sociólogo insobornable y de un erudito cooperativista. Prueba de esto último es todo el desarrollo de esta doctrina y las dos alusiones que hace al 'espíritu de Rochdale', que demuestra le era bien conocido» ${ }^{\text {. }}$

Abre y cierra su dictamen acerca de la cooperación de consumo con la misma imagen: es la verdadera piedra filosofal, explicándolo así al principio: «Por una alquimia económica, los gastos se trasmutan en ingresos, el ahorro es engendrado por el mismo gasto y conviértese en fuente de capital lo que hasta aquí ha sido causa de pobreza: la piedra filosofal del siglo XIX» (O.C. V).

Posiblemente por este artículo de don Joaquín, o por conversaciones con don Eugenio llegó a conocimiento de Montero Ríos la preocupación que sentía su buen amigo por el tema, entonces tan novedoso, del cooperativismo. De ahí que siendo Ministro de Fomento, durante el bienio 27VI-1885 a 9-X-1886, le encargase a Rábago la redacción de un Proyecto de Ley de Sociedades Cooperativas que el célebre político santiagués habría de presentar ante el Congreso de los Diputados. Pero la brevedad de su mandato ministerial hizo que dicho Proyecto no saliese adelante, 
«quedando olvidado en algún despacho de la administración. España perdió de esta forma la ocasión de adelantarse en casi medio siglo -el tiempo que va desde 1885 a 1931 - con una ley de cooperativas» ${ }^{6}$.

Mas, este Proyecto de Ley de Sociedades Cooperativas, manuscrito de puño y letra de don Joaquín, se conservó en la biblioteca de su pazo de La Puebla y permaneció ignorado hasta que lo descubrió allí Luis Fernández de la Fuente, S.J., noventa años después de ser escrito, cuando estaba reuniendo materiales para su tesis doctoral sobre «el pensamiento social de D. Joaquín Díaz de Rábago». Parece ser que el manuscrito sufrió varias redacciones y revisiones, aunque con variantes muy leves, que no afectan a la substancia del contenido. La autoría del manuscrito de don Joaquín, copia del primer original, aparece corroborada a su final por su hijo, don Andrés: «Sin la menor duda afirmo que la letra de este escrito es la de mi padre don Joaquín Díaz de Rábago y Díaz de Mier fallecido el 29 de julio de 1898». Lo afirmaba en Santiago el 28-VIII-1969.

Consta el proyecto redactado por Díaz de Rábago de dos partes: una «Exposición de motivos» y el «Articulado». La primera viene a ser una monografía acerca de la cooperación, en la cual estudia el tema en su conjunto y en cada una de sus cuatro ramas; o sean, las cooperativas de consumo, de producción, de crédito y de construcción. Analiza su evolución histórica en distintos países europeos y en Norteamérica, haciendo un admirable estudio de legislación comparada para insertar su proyecto de ley dentro de la normativa legal española con la máxima modernidad y eficacia ${ }^{1}$.

Siete años después las líneas generales del frustrado proyecto sirvieron de fundamento a una ponencia leída en el $I V^{o}$ Congrés des Societés Francoises de Credit populaire; reunido en Lyon del 4 al 7 de mayo de 1892. El informe escrito por encargo del tratadista M. Durand, se titulaba Basses Essentielles d'une loi sur les Societés Cooperatives y fue leído en la sesión del 5 de mayo; motivó la admiración de los grandes especialistas en la materia, que ya habían honrado a don Joaquín eligiéndole para una de las vicepresidencias del Congreso. Fue impreso el rapport de Rábago aquel mismo año en Angers y, en su original español, en Madrid.

Plantea Díaz de Rábago, en sus Bases especiales de una ley de Sociedades Cooperativas (O.C. VIII), diversas cuestiones de tipo jurídico: si las cooperativas son meras asociaciones regidas por normas de derecho privado o son verdaderas sociedades subordinadas al derecho público, 
inclinándose por esto último; si son civiles o comerciales; si son colectivas, anónimas o comanditarias, admitiendo que tienen algo de las dos primeras, pero que no se identifican con ninguna de ellas y por tanto deben regirse por una ley especial y propia» ${ }^{1}$.

En su obra fundamental, El Crédito Agrícola, ya había examinado Díaz de Rábago el «sistema cooperativo aplicado al crédito, de los renombrados banco populares o de anticipos, considerados por entendidos economistas como fórmula satisfactoria y, experimentada no solamente del crédito obrero, sino del de la pequeña industria y por tanto del cultivo y del de todas aquellas clases a quienes los bancos ordinarios dejan actualmente en desamparo», escribía en el tercer volumen de su magna obra (O.C. III).

Pues bien, once años más tarde -Julio, 1894- publica en la imprenta Paredes de Santiago, un opúsculo acerca de Las Cajas rurales de préstamos, Sistemas Raiffeisen (O.C. VIII) que Rábago había sido el primero en dar a conocer en España. Consta la monografía de cuatro apartados; los dos primeros dedicados al aspecto económico y los dos últimos a su cariz moralizador. Rectifica en ellos su criterio, expuesto en El Crédito Agrícola, favorable al sistema Schulze-Delitzch; ahora se pronuncia decididamente por el sistema de Raiffeisen que mantiene «en toda su pureza el sistema cooperativo». «Hombre de corazón Raiffeisen ha inventado un excelente aparato económico, con la intención puesta en mira más alta. En su mente, el dinero no es el fin de las Cajas Rurales, sino medio...», conceptúa don Joaquín.

El entusiasmo de Díaz de Rábago por el sistema cooperativo, considerándolo como la piedra filosofal para resolver el problema del consumo en las clases trabajadoras, o como una posible solución para el desarrollo del crédito agrario, también se extiende hacia la modalidad del cooperativismo en la producción, exaltándolo en La Industria de la Pesca en Galicia (O.C. V), y en cuanto al cooperativismo de la construcción que considera el modo de solucionar El Problema social de la habitación, en el último discurso que pronunció, titulado así (O.C. VIII).

Sin embargo Rábago advertía repetidamente en sus escritos que la cooperación no constituía una panacea absoluta. «La cooperación -decía, por ejemplo, al tratar de Las Cajas de Préstamos- nunca llegará a ser la fórmula de la organización económica de la sociedad, ni mucho menos posee la virtud de producir una renovación moral y social, que hasta ese punto han llevado la exageración algunos de sus panageristas» (O.C. VIII). 
Pero era, sin duda para don Joaquín «una fórmula nueva socioeconómica de conciliación entre el capital y el trabajo, superadora del liberalismo y del marxismo que los enfrentan» ${ }^{1}$.

El resonante triunfo de Rábago en el Congreso de Lyon le valió ser invitado poco tiempo después por Mr. Henry W. Wolff al Congreso de Londres, organizado por la Coopérative International Alliance y promovido por ese ilustre sociólogo. Mr. Wolff invitaba a Díaz de Rábago a que redactase una Memoria sobre la «Historia y situación actual de la cooperación en España». Cumplió el encargo don Joaquín con gran diligencia y la Memoria fue acogida en el Congreso cooperativo «con extraordinario aplauso y, traducida al inglés, mereció ver la luz pública en el elegantísimo tomo en que constan los trabajos del Congreso londinense, que llevan al frente el retrato del autor de cada uno de ellos» ${ }^{1}$. Hecha por el propio Mr. Wolff la foto de D. Joaquín que aparece en aquel, luego tan reproducida.

Divide Díaz de Rábago en tres épocas su breve historia del cooperativismo español: la anterior a la Revolución de septiembre de 1868, la revolucionaria que se cierra con la restauración de la dinastía borbónica y la contemporánea a partir de 1875, en que comienza el reinado de Alfonso XII. Ya en sus primeras líneas muestra las fuentes en que bebió para componer su trabajo histórico: «el infatigable don Fernando Garrido, autor de un folleto de ardiente propaganda titulado La Cooperación; el exministro don Manuel Pedregal Cañedo en su libro Sociedades Cooperativas; y el catedrático de la Universidad Central, don José Piernas Hurtado, que ha publicado, coleccionadas y con interesantes apéndices, tres conferencias dadas en el Fomento de las Artes sobre El movimiento cooperativo» (O.C. VII).

De todos estos opúsculos, base de la monografía de Rábago, trato en las respectivas biografías de «Los varones de la Cooperación en España» que componen una posible Galería de revolucionarios de antaño. Pero la aportación mayor que hizo don Joaquín a la historia del cooperativismo español es el aprovechamiento de los datos que constaban en los Registros especiales existentes en los Gobiernos civiles de las provincias, creados por la ley -30-VI-1887- sobre ejercicio del derecho constitucional de asociación.

La conclusión que extrae Díaz de Rábago de su Memoria es que hasta entonces había sido escaso el desarrollo de la Cooperación en España,

"CUADERNOS DE ESTUDIOS GALLEGOS", Tomo XLV, Fascículo 110, Santiago 1998. 
debido a la corta iniciativa de la clase obrera, a su poca tenacidad, a su falta de educación económica y a su ignorancia de los medios cooperativos a su alcance (O.C. VII). Aunque don Joaquín, como Diógenes, quizá buscase con su linterna al hombre providencial:

"¿Quéfalta, pues? -se preguntaba en su monografía sobre Las Cajas Rurales de Préstamos-Nada y todo: un hombre, uno nada más que sienta hervir en su interior la vocación de este apostolado. Acaso ni aún eso sea necesario: acaso baste con el ejemplo de una persona de notoriedad, de las que por su prestigio son verdaderas autoridades sociales, como las llama Le Play, que arrastran a los de cerca e inducen a los de lejos» (O.C. VIII).

\section{EL LIBERAL CATÓLICO DE LA PUEBLA}

A D. Joaquín Díaz de Rábago «nadie tenía por suyo, porque era de todos: admirador de Azcárate, discípulo de Sanromá, lector de Fernando Garrido, amigo de Montero Ríos. Sus mismos esfuerzos conciliadores entre el capital y el trabajo en un país tan proclive a posturas extremas. Y más que nada su acendrado catolicismo por encima de todas las ideologías» ${ }^{1}$. Este espíritu piadoso de D. Joaquín ha sido seguramente lo que evitó que su pensamiento estuviera dominado por un elegante eclecticismo. Aunque el liberalismo fue su ideología inicial, nunca pudo decirse de la actitud de Rábago que fuese la de un escéptico -como solía atribuirse a los liberales-en política y en religión.

Su liberalismo era «de origen ambiental y universitario. Fue discípulo del maestro Sanromá y a su vez Sanromá fue el maestro predilecto de Rábago. Sanromá era liberal; y liberal fue también su discípulo. Algo análogo le ocurrió con Jovellanos. Éste era liberal, y sus escritos dejaron huella liberal en el lector Díaz de Rábago. Buen testimonio de ello es la cita de Jovellanos que pone al frente de su discurso sobre La Tasa legal de los productos. En cuanto a su liberalismo económico es también clara la influencia de Adam Smith y la de los fisiócratas franceses Federico Bastiat y Juan Bautista Say».

«Esta influencia liberal predominó en él en su edad juvenil y, aunque perduró hasta el fin de su vida, fue siendo paulatinamente desplazada, a 
medida que se afirmaba su personalidad, por la filosofía cooperativista bajo el influjo de Raiffeisend y de Mr. Durand, sobre todo en lo relativo a la cooperación de crédito. Para su catolicismo social no hace falta buscar influencias extrañas. Le salía de dentro. Si acaso señalar su fiel sintonía con las enseñanzas de la Iglesia, como las de la encíclica Rerum Novarum, las cuales no hacían más que confirmar sus propias ideas»1.

«La vida del insigne economista, sobre todo en los últimos años -apunta Cabeza de León- fue una continua sucesión de tremendos dolores, que sin darse tregua cayeron sobre aquel ánimo varonil, fortaleciendo en él, a cada nueva sacudida, la fe cristiana, la confianza en Dios y el acatamiento sumiso a los decretos del Altísimo» ${ }^{5}$.

Vida paralela pues a la del otro varón de dolores, don Gumersindo Laverde, que compartía sus sufrimientos con Rábago «en aquel minúsculo Areópago» compostelano del que el sabio maestro de Menéndez Pelayo «era Pontífice máximo», según recordaba Barcia Caballero ${ }^{6}$. Este mismo médico y poeta así como los demás miembros del Areópago -Brañas, Cabeza, etc.- fieles amigos de Díaz de Rábago, despidieron, en el aciago verano de 1898, a don Andrés cuando «aprovechando levísima tregua de su mal incurable decidió trasladarse a su casa del Caramiñal por la que siempre suspiraba».

«Cuantos entonces le despedimos, abrigamos el convencimiento de que aquel era su último adiós. Y así fue. En aquella mansión de delicias, donde había sentido las mayores de su vida: en aquel pintoresco lugar creado por todas las brisas del mar que lo acarician y refrescan, y perfumados por todos los aromas que lo embalsaman, fue a dormir su último sueño al lado de las prendas más queridas de su alma. Pocos días antes le precediera su primogénito, amigo queridísimo, víctima del propio mal, cuando se abrían ante él las doradas puertas de un porvenir glorioso», dejó constancia la pluma neorromántica del propio Barcia $^{2}$.

Los periódicos santiagueses publicarían esquelas puestas por las entidades santiaguesas que D. Joaquín tanto había servido y honrado: la Sociedad Económica, la Escuela de Artes y Oficios, las Conferencias de San Vicente del Paúl y la sucursal del Banco de España que Rábago había dirigido eficazmente desde su fundación hasta su muerte, el 29 de julio de 1898. Dos días después publicó Barcia Caballero su nota necrológica en El Eco de Santiago, y lo mismo hizo Alfredo Brañas en otro diario. En 
ellas ambos abogaban porque se hiciera una edición de las obras completas de Díaz de Rábago.

Estudiaban el modo de llevar a cabo ese propósito cuando les sorprendió gratamente la noticia de que la Sociedad Económica, a propuesta de su director, el catedrático de Derecho Penal, D. Ramiro Rueda, iba a realizar tal edición, encomendando a Barcia y a Brañas -tal vez por haber vertido la idea- su preparación, junto con Salvador Cabeza, antiguo secretario de la Económica. Pronto hicieron su trabajo, pues ya al año siguiente de la muerte de don Joaquín, salió el primer volumen de El Crédito Agrícola, que constituye el primer tomo de las Obras Completas, preludiado por la escueta biografía de Rábago, escrita por Barcia, y el largo estudio crítico de sus obras económicas, hecho por Brañas.

La edición de las Obras Completas, compuesta de ocho tomos se imprimió con esmero y rapidez en la tipografía y litografía santiaguesa de José M. Paredes, pues en 1901 quedó concluida. Apareciendo en el último volumen el prólogo de Cabeza de León en que comenta las obras de Rábago que Brañas no había estudiado en el primer tomo. Entretanto, como señala dolorosamente D. Salvador, había muerto Alfredo Brañas, en plena madurez intelectual y dejando la tarea de completar la edición de las obras de don Joaquín a sus otros fieles y devotos amigos.

Había merecido don Joaquín Díaz de Rábago, por su vida y por su obra, que la Reina Regente le concediese, a propuesta de su ministro Montero Ríos, la Gran Cruz de la Real Orden de Isabel la Católica. Era la condecoración que ostentaba su cuerpo presente en la capilla ardiente de la Soledad, en la iglesia de Santiago de Deán, cuyo Patronato correspondía a su linaje. Queda escrito que su primogénito le precedió, por unos días en su tránsito a la vida eterna. Mas, la estirpe del piadoso señor santiagués, como se apuntó en el capítulo correspondiente, prosiguió honrosamente en la demás descendencia. Entre ella, la de su hija Carmela, madre de la Condesa de Fenosa, doña Carmela Arias Díaz de Rábago, viuda de Pedro Barrié, creador éste de la acaudalada Fundación que ella preside. Y la de su hijo don Andrés, el bondadoso y simpático compadre de don Ramón del Valle-Inclán; progenitor a su vez, de dos sacerdotes jesuitas; uno de ellos, Andrés como su padre, misionero en China y en la isla de Timor, muerto muy joven en Inglaterra; dicen que en olor de santidad, por lo cual creo recordar que se inició hace ya muchos años su proceso de beatificación. De ahí que repita la expresiva frase oída en

"CUADERNOS DE ESTUDIOS GALLEGOS", Tomo XLV, Fascículo 110, Santiago 1998. 
labios de devotas ancianas santiaguesas y de La Puebla de Deán, evocando así a su santo y sabio abuelo: ¡Bendita la rama que al tronco tira!.

\section{BIBLIOGRAFÍA}

${ }^{1}$ FERNÁNDEZ DE LA FUENTE, S.J., LUIS. Un eminente sociólogo gallego: Joaquín Díaz de Rábago (1937-1898). Pionero del cooperativismo en España. Caja Rural de Orense. Madrid, 1978.

${ }^{2}$ BARCIA CABALLERO, JUAN. «Excmo. Sr. D. Joaquín Díaz de Rábago. Apuntes biográficos». Tomo I de las Obras Completas de éste.

${ }^{3}$ COTARELO Y VALLEDOR, ARMANDO. Memorias de un escolar de antaño (1808-1809) Tomo I, Palladis tyrones. Tomo II, La enseña radía. Madrid, 1921.

${ }^{4}$ BRAÑAS MENÉNDEZ, ALFREDO. «El Excmo. señor D. Joaquín Díaz de Rábago y sus obras económicas». Tomo I de las Obras Completas de éste.

${ }^{5}$ CABEZA DE LEÓN, SALVADOR. «Prólogo» a las Obras Completas de D. Joaquín Díaz de Rábago. Tomo VIII de éstas.

${ }^{6}$ OTERO GULDRÍS, FRANCISCO. «Díaz de Rábago y Díaz de Mier, Joaquín Antonio». Artículo correspondiente en la Enciclopedia Gallega.

${ }^{7}$ DOMÍNGUEZ FONTÁN, MANUEL. La Puebla del Caramiñal. Un mirador sobre la Ría de Arosa (Contornos Geográficos, Historia, Tradiciones). Vigo, 1962.

${ }^{8}$ BOROBÓ. El fantasma de Valle-Inclán. Edicións do Castro. Sada. A Coruña, 1986.

${ }^{9}$ A. ELORZA y C. IGLESIAS. «Apéndice» a Burgueses y Proletarios. Clase obrera y reforma social en la Restauración.

"CUADERNOS DE ESTUDIOS GALLEGOS", Tomo XLV, Fascículo 110, Santiago 1998. 
${ }^{10}$ DOMMANGET, MAURICE. Historia del $1^{\circ}$ de Mayo. Trad. de Marta Guastavino. Edit. Laia, 1976.

${ }^{11}$ PEDRET CASADO, PAULINO. Verbas limiares a Novelas de López Ferreiro. Biblioteca de Galicia VII. Bibliófilos Gallegos. Santiago de Compostela, 1953. 